\title{
Psicanálise e Ciência
}

Psychoanalysis and Science

Regina Coeli Aguiar Castelo Prudente \& Maria Anita Carneiro Ribeiro

Centro de Ensino Superior de Juiz de Fora-MG
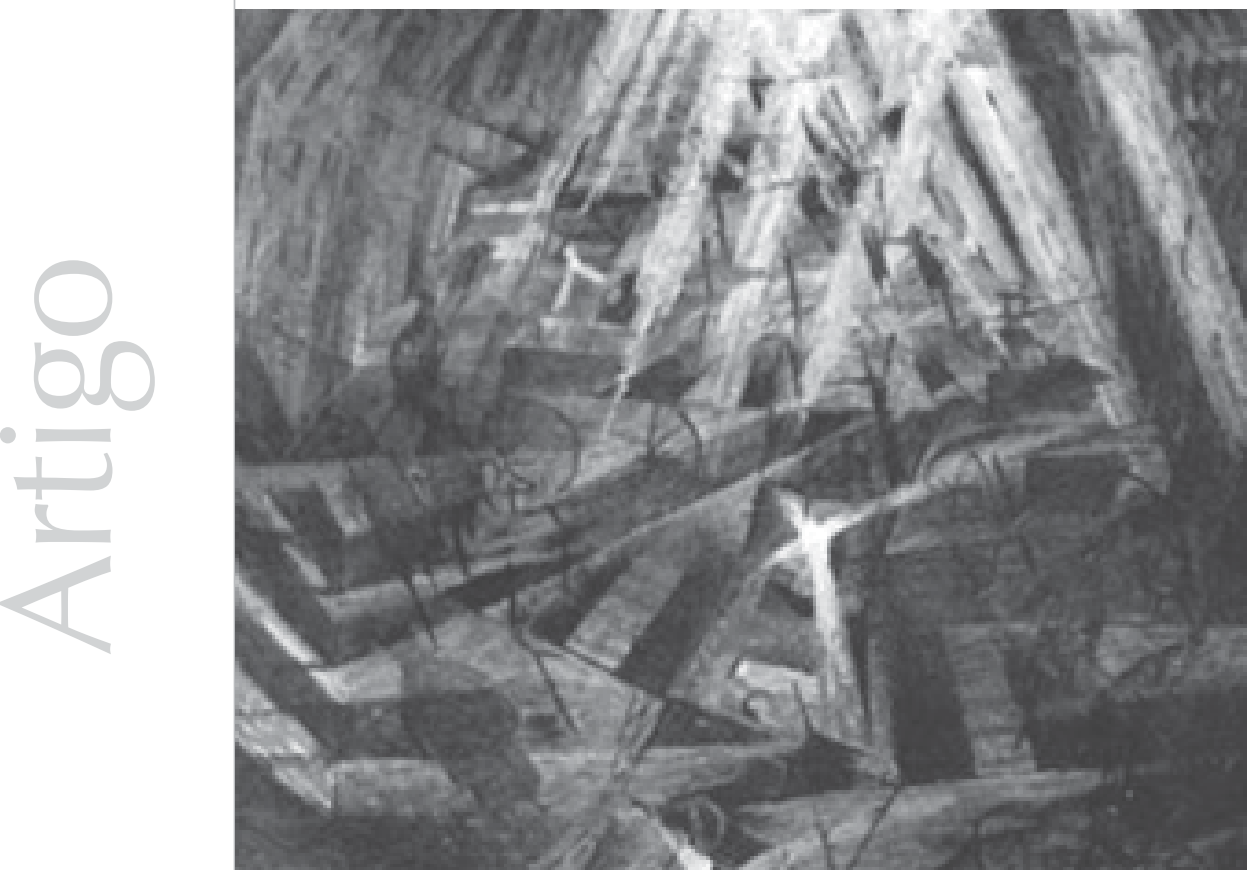


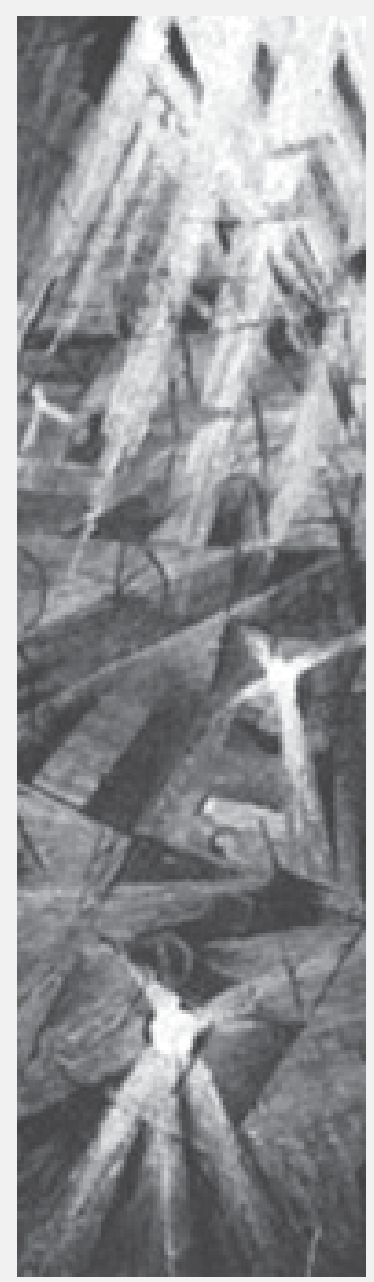

Resumo:Embora Freud tenha sido um cientista, formado no espírito científico de sua época, as relações da psicanálise com a ciência nunca foram fáceis. Desde o "Projeto", de 1895, até seus últimos textos, Freud nunca abandonou seu propósito de fazer com que a psicanálise fosse reconhecida como ciência. Jacques Lacan, a partir de sua teoria dos discursos, afirma que a psicanálise é um novo campo do saber que mantém conexões com o campo de saber da ciência, mas com ele se confunde. O sujeito da psicanálise é o mesmo sujeito da ciência - o sujeito do desejo - mas Freud subverte o cogito cartesiano ao descobrir o inconsciente.

Palavras-chave: psicanálise, ciência, saber.

Abstract: Although Freud has been originally a scientist, formed on the scientifical spirit of his age, relationship between psychoanalysis and science has never been an easy matter. Since his "Project", from 1985, to his last texts, Freud has never left down his purpose to have psychoanalysis accepted as a legitimate science. Jacques Lacan, starting from his own theory of the discourse, confirmed psychoanalysis as a new field of knowledge which has some connections with the scientifical field of knowledge, but cannot be mixed up with it. The subject of psychoanalysis is the same as of science - the subject of the desire - but Freud, with his discovery of the unconscious mind, brings a subversion to the cogito of René Descartes.

Key-words:psychoanalysis, science, knowledge.

\section{Com Freud}

“Nossa ciência não é uma ilusão. Ilusão seria imaginar que aquilo que a ciência não nos dá podemos conseguir em outro lugar" (Freud, [1927] 1974, v. XIX).

Nosso objetivo, na abordagem sobre a questão da psicanálise e da ciência, é verificar como a psicanálise conquista para a ciência um novo continente - o do psiquismo inconsciente - e como esse inconsciente, erigido como objeto, não era nada de que a ciência do tempo de Freud pudesse dar conta e, muito menos, a ele conferir legitimidade científica.

Partiremos do conceito de "ciência normal", tal como Thomas S. Kuhn a descreve, o que vem a significar "a pesquisa firmemente baseada em uma ou mais realizações científicas passadas expostas e relatadas em manuais científicos elementares ou avançados" (1970, p. 101). Esses manuais e livros tornaram-se bastante populares no começo do século XIX. Entre eles, podemos
"Nossa ciência não é uma ilusão. llusão seria imaginar que aquilo que a ciência não nos dá podemos conseguir em outro lugar" 
exemplificar: o "Princípio e a óptica", de Newton, a "Eletricidade", de Franklin, e a "Química", de Lavoisier, entre outros, que serviram, por um longo tempo, para definir implicitamente os problemas e os métodos legítimos de um campo de pesquisa para uma geração de praticantes da ciência.

Ainda, para melhor esclarecer seu conceito de "ciência normal", Thomas Kuhn irá lançar mão de exemplos aceitos na prática científica, que incluem, ao mesmo tempo, lei, teoria, aplicação e instrumentação, gerando modelos dos quais brotaram as tradições coerentes e específicas 'da' pesquisa científica, tais como a "Astronomia Copernicana" e a "Dinâmica Aristotélica" ou "Newtoniana", entre outros modelos ou paradigmas muitas vezes bem mais especializados.

Apresentaremos, neste estudo, a psicanálise como promotora de uma revolução científica que terá início no momento em que "o paradigma existente deixou de funcionar adequadamente" (Kuhn, 1970, p. 126).

Ao promover um corte paradigmático através de seus conceitos, a psicanálise gera um complicador, na medida em que seus pressupostos anunciam que essa ciência se ocupa, sobretudo, da subjetividade num tempo em que a exigência era a de se atingir um conhecimento objetivo e generalista.

A experiência do sujeito, sua história, não são dados que poderiam fornecer um critério suficiente de credibilidade e legitimidade científicas, cabendo à psicanálise uma definição muito mais próxima às ciências "semiológicas ou históricas, pois se define muito mais por ser uma ciência exegética, hermenêutica ou interpretativa", de acordo com Japiassu (1989, p. 28).

A formação intelectual de Freud dar-se-á numa atmosfera positivista e cientificista típicas do século XIX. O espírito positivo, testemunhado pelo impulso que toma a história natural do homem em detrimento da condição que conferia uma visão teológica do mundo, se afirmava. Além do mais, no século XIX, a crença no conhecimento científico como o supremo poder resolutivo dos males do mundo “crença que Freud guardou por toda a vida estava principiando a deslocar as esperanças que se haviam erguido a favor da religião, da ação política e da filosofia, alternativamente. Freud estava altamente imbuído de tudo isto" (Jones, 1961, p. 121).

Ernst Jones nos aponta que o conflito entre entregar-se irrestritamente ao exercício do pensamento e ao jogo da fantasia à necessidade de submeter-se a uma disciplina científica terminou em uma "inequívoca vitória desta última" (ibid., p. 122).

Freud jamais abriu mão de seu projeto de tornar a psicanálise uma ciência. Em uma pequena nota sua, datada de 1920, “Uma nota sobre a pré-história da técnica de análise" (Freud, 1976, v. XVIII), faz uma incisiva réplica às críticas de Havelock Ellis, pesquisador da ciência sexual e crítico da psicanálise, que, em um ensaio de 1919 ("The philosophy of conflict to sex"), inclui um artigo cujo objetivo é demonstrar que os escritos do fundador da análise não devem ser julgados como uma peça de trabalho 
científico, mas, sim, como uma produção artística. Freud considera a apreciação de $\mathrm{H}$. Ellis como resistência e repúdio à análise, "ainda que se ache disfarçada sob forma amistosa e, na verdade, lisonjeante demais" (Freud, 1976, v. XVII, p. 315).

Freud inicia esse trabalho afirmando sua disposição de enfrentar tais afirmações com a mais decidida oposição e o finaliza apontando a importância da leitura de Ludwig Börne, autor que the fora apresentado quando, aos quatorze anos de idade, foi presenteado com suas obras completas; Freud afirma que Börne foi o primeiro autor cujos escritos o afetaram profundamente e que ficara espantado em se encontrarem expressas, em seu conselho a um escritor original, algumas opiniões que ele próprio sempre prezara.

Uma covardia vergonhosa com relação ao pensar nos retém a todos: a censura do governo é menos opressiva que a censura exercida pela opinião pública sobre nossas produções intelectuais. Não é a falta de intelecto, mas de caráter que impede a maioria dos escritores de serem melhores que são (Börne apud Freud, [1920] 1976, v. XVII, p. 317).

Às críticas de seu tempo em relação a seu anseio de ser homem da ciência, Freud reagiu com vigor. Em seu manuscrito de 1895, «Projeto para uma Psicologia Científica», já no primeiro parágrafo, apresenta sua intenção: «a finalidade deste projeto é estruturar uma psicologia que seja uma ciência natural, isto é, representar os processos psíquicos como processos quantitativamente determinados de partículas materiais específicas» (Freud, [1895] 1976, v. I, p. 403).
A primeira grande Revolução promovida pela psicanálise ocorrerá a partir da descoberta da motivação inconsciente nas ações humanas e da sexualidade infantil. Por essas duas vias, um corte é proposto e lançado através de um conjunto de questões que, além de sustentarem toda a pesquisa psicanalítica, irão fornecer-lhe material e recurso teórico extraídos da escuta clínica.

No ano de 1874, o médico Moritz Benedikt apresentou sua idéia a propósito do que seria a discussão entre a experiência direta e a fundamentação científica no capítulo dirigido ao método sobre o tratamento da histeria.

As ciências clínicas têm peculiaridades visà-vis das ciências naturais; elas têm de ocupar-se da prática enquanto base para o entendimento teórico da mesma, a saber, sobretudo a anatomia e a fisiologia ainda acusam lacunas enormes. A essência do clínico precisa ser outra que não o pesquisador das ciências da natureza, mais exatas (apud Lorenzer, 1984, p. 71).

A observação de Benedikt, anos antes de Freud surgir como autor, antecipa uma das grandes questões da psicanálise: a clínica da escuta, que, "rompendo com aquela do olhar, incessantemente invocada por seu empirismo, a modéstia de sua atenção e o cuidado com que permite que as coisas silenciosamente se apresentem ao olhar, sem perturbá-la com discurso" (Foucault, 1998, p. 4).

A invenção da escuta do inconsciente proposta pela psicanálise rompe com a Medicina da época, que propunha uma correspondência exata do "corpo" da doença com o corpo do homem doente. Era esse o modelo da Medicina que vigorava no século
A essência do clínico precisa ser outra que não o pesquisador das ciências da natureza, mais exatas 
XIX, aquele que concedia todo privilégio à anatomia patológica.

Michel Foucault nos descreve essa época como aquela que marca a soberania do olhar, em uma experiência que lê, de uma só vez, "as lesões visíveis do organismo e a coerência das formas patológicas; o mal se articula exatamente com o corpo e sua distribuição lógica se faz, desde o começo, por massas anatômicas" (ibid.). "O golpe de vista" precisa apenas exercer a verdade no lugar onde ela se encontra, um poder que, de pleno direito, ele detém (ibid., p. 2).

Ninguém, além do próprio Freud, dará início à grande discussão em torno da inscrição da psicanálise no campo das ciências, a partir, essencialmente, do seu desejo cientificista, do qual jamais irá abrir mão, sem dar conta, pelo menos a princípio, da impossibilidade de sua pretensão ser derivada da especificidade do conhecimento que construiu.

Já no ano de 1895, em Estudos sobre a Histeria, pode-se verificar a busca de Freud por uma inscrição no campo das ciências (Freud, [1893-1895] 1974, v. 11). Na apresentação dessa obra, James Strachey, tradutor da obra freudiana para o inglês, observa que as divergências entre os autores, Freud e Breuer, não são ainda observadas, apesar de já existirem. A decisão de publicação conjunta foi resultado de um acordo destinado a mostrar à comunidade científica o trabalho realizado pelos dois autores até 1894, época em que a relação científica já havia acabado, visto que Freud já sustentava a idéia de uma "defesa psíquica" no sintoma histérico e Breuer pensava em uma fisiologia dos "estados hipnóides". Além do mais, Breuer recusouse a atribuir à histeria uma etiologia puramente sexual. Logo após a publicação dos Estudos sobre a Histeria, Freud inicia a redação do "Projeto para uma psicologia científica", artigo escrito em 1895, cuja publicação só se realizará em 1950, onze anos após sua morte.

No texto desse artigo, Freud tentará demonstrar empiricamente, através de um modelo mecanicista da física, a sua ciência, abordando em ótica distinta "muitas das questões que a filosofia que o antecedeu tratava em outro contexto", comenta Luiz A. Garcia Roza (1996, p. 42) em sua avaliação sobre o "Projeto", em Freud e o Inconsciente.

Para alguns, a psicanálise tem início com o "Projeto"; para outros, essa obra é uma desesperada tentativa de argumentar através de uma linguagem fisicalista exigida pela época, segundo Garcia Roza. A proposta de Freud é, de acordo com sua própria afirmação, a de elaborar uma "teoria do funcionamento psíquico segundo uma abordagem qualitativa e quantitativa, uma espécie de economia da força nervosa" (Freud, [1895] 1976, v. I, p. 403), proposição que manterá durante toda sua obra.

Sem pretendermos nos colocar ao lado daqueles que assinalam ser o "Projeto" a obra que dará início à psicanálise, nem tampouco em seu extremo, entre aqueles que assinalam ser essa obra o último suspiro de um pensador, colocamo-nos, sim, na posição de afirmarmos a importância vinculada à tentativa de inscrição de Sigmund Freud na cena da ciência de sua época. Essa obra far-se-á presente em todo o seu trabalho posterior, bem claramente observável no capítulo VII de A Interpretação dos Sonhos e em "Além do Prazer", de 1900 
e 1920 respectivamente, obras vitais para a compreensão do saber que a psicanálise irá inaugurar.

As críticas relativas à cientificidade da psicanálise são radicais e partem especialmente de epistemólogos oriundos do empirismo lógico, preocupados com "a lógica da explicação". Japiassu discute, em Psicanálise: Ciência ou Contra-ciência?, de 1989, que os críticos que sustentam suas abordagens a partir do empirismo lógico e do racionalismo crítico de Karl Popper indagam se a psicanálise constitui uma "teoria" propriamente científica, isto é, se se apresenta através de um conjunto de proposições que sistematiza, explica e prevê, em certos fenômenos observáveis, e se deve satisfazer às mesmas regras lógicas de uma teoria científica. Afirmam os empiristas: "parece que não podemos deduzir nada de preciso das noções 'energéticas' do freudismo, posto que são vagas e metafóricas. São noções sugestivas, mas não susceptíveis de validação empírica" (Japiassu, 1989, p. 26).

A cientificidade da psicanálise discutida ao longo de sua existência terá, na década de sessenta, seu maior defensor teórico no filósofo francês L. Althusser. Em sua formulação, "a psicanálise se constituiria efetivamente como discurso científico, na medida em que produziu um objeto teórico articulado de maneira coerente por um método de investigações e por uma técnica" (ibid., p. 27).

Althusser inscreve-se como epistemólogo da tradição francesa da filosofia da ciência, que se inicia na década de trinta, com Gaston Bachelar, de acordo com o texto de Joel
Birman em sua obra Psicanálise, Ciência e Cultura, no qual o autor ainda esclarece que tal discurso epistemológico se fez a partir de uma crítica radical da filosofia positivista da ciência, curiosamente também iniciada na França através de um dos grandes filósofos que tal nação irá produzir, Auguste Comte.

L. Althusser não só contra-atacou as críticas que visavam a descaracterizar a cientificidade da psicanálise como também denunciou a tentativa de apropriação dos conceitos psicanalíticos pelos discursos filosóficos, subtraindo-Ihes a originalidade teórica. A legitimidade dessa ciência é conferida pela via de seu objeto teórico, o inconsciente, que realizou o corte epistemológico com a tradição da Psicologia da consciência e com a psiquiatria do final do século XIX e início do século XX.

Foi no ano de 1900, com a publicação de $A$ Interpretação dos Sonhos, que Freud apresentou o conceito de inconsciente e demarcou o nascimento da psicanálise, apresentando o seu sujeito, radical em sua construção, pois subverte aquele oriundo do cogito cartesiano por ser pulsional por excelência. A razão, coincidindo com a consciência, é colocada em questão, e ninguém, além do próprio Freud, apontou melhor para esse rompimento quando declara ser a psicanálise a terceira grande ferida narcísica sofrida pelo saber ocidental. O saber da ciência psicanalítica construiu um objeto cujo vigor e cuja verdade estão sustentados na subversão dos propósitos de objetividade e controle que toda ciência advoga, e, por isso, exige revisão de cânones, atraindo para si, dentro do campo científico, toda a espécie de resistência.
A cientificidade da psicanálise discutida ao longo de sua existência terá, na década de sessenta, seu maior defensor teórico no filósofo francês L. Althusser 
Sigmund Freud apresenta uma ciência singular que propõe um sujeito também singular, único, e que exige algo para além da evidência sistemática, a qual explica coisas que o ser humano faz e sente por meio de especulações que podem parecer estranhas à maioria. A psicanálise raciocina para além da ciência dita normal, o que não significa um demérito a uma ou outra. Apontamos, sim, para a diferença, para o lugar que, segundo nossa avaliação, seria o da psicanálise que, apoiada em outros fundamentos, estaria reivindicando uma outra forma de prova científica diferente daquela proposta pelas ciências do século XIX.

Freud, sabemos, foi pesquisador de laboratório e deixou-nos escrito, em seu artigo "Um estudo autobiográfico", de 1924, um texto valioso para nosso argumento, revelando-se o entusiasmado pesquisador das ciências naturais que, sem dúvida, foi:

Por fim, no laboratório de fisiologia de Ernst Brücke, encontrei tranqüilidade e satisfação plena - e também os homens que pude respeitar e tornar como meus modelos, o próprio grande Brücke e seus assistentes, Sigmund Exner e Ernst von Marxow. Com Brücke, um homem brilhante, tive o privilégio de manter relações de amizade (Freud, [1925-1926] 1976, v. XX, p. 20).

Esse verbete de 1922 escrito antes de Freud remoldar suas opinióes sobre a estrutura da mente proposta em o "Ego e o Id", de 1923 emborajápossam ser claramente observadas as articulações com esse texto. No Congresso Psicanalítico Internacional em Berlim, em setembro de 1922, é mencionado que, nesse verbete, Freud torn públicas as concepções de ego, superego e id, que acabara de formular. em que se encontrava, aconselhando-o a abandonar rapidamente a carreira teórica desenvolvida no laboratório e ingressar na Medicina.

No verão de 1922, Freud escreveu, para uma enciclopédia, dois verbetes: "Psicanálise" e "Críticas e más interpretações da psicanálise". Ambos nos interessam, especialmente por apresentarem, didaticamente, os temas como requer uma escrita para tal fim.

Em "Críticas e más interpretações da psicanálise", Freud discute que a maioria do que é apresentado contra a psicanálise, mesmo em obras científicas, baseia-se em informações insuficientes que parecem "ser determinadas por resistências emocionais" (Freud, [1922] 1974, v. XVIII, p. 305). Formaliza, ainda, sua posição de apresentar a psicanálise enquanto ciência, alegando tratar-se de um equívoco acusarem sua teoria de "pansexualismo" e afirmando que ela não deriva de todas as ocorrências mentais da sexualidade nem remonta todas àquela. Salienta que a psicanálise jamais "sonhou" tentar explicar tudo, e mesmo as neuroses não têm sua origem somente na sexualidade, mas também no "conflito entre os impulsos sexuais e o ego" ${ }^{1}$ (Freud, [1922] 1974, v. XVIII, p. 306).

Ao defender a ciência psicanalítica da acusação de unilateralidade, acusação advinda a partir de sua apresentação de ser a "ciência da mente inconsciente" (ibid., p. 305) e que, por isso, tem seu campo de trabalho definido e restrito, replica que tal argumento lhe é "tão injusto quanto seria se houvesse sido feita tal acusação à química" (ibid.). 
Em 1915, Freud apresenta uma exposição completa e sistemática de suas teorias psicológicas quinze anos após haver apresentado um relato ampliado desses conceitos no sétimo capítulo de A Interpretação dos Sonhos, que, de certa forma, incorpora o que ele já teria proposto em seu "Projeto para uma Psicologia Científica".

Os cinco artigos meta-psicológicos, apresentados entre 1915 e 1917, formam uma série interligada, cuja intenção, segundo o editor, é proporcionar um fundamento teórico estável à psicanálise. No primeiro artigo, "Os instintos e suas vicissitudes", Freud inicia sua argumentação assinalando que, com freqüência, ouvimos a afirmação de que as ciências devem ser estruturadas em conceitos básicos claros e bem definidos. Todavia, nenhuma ciência, nem mesmo a mais exata, começa com tais definições. Ressalta, ainda, que o primeiro objetivo de uma atividade científica, que consiste na descrição do fenômeno, não poderá evitar que nele se apliquem certas idéias abstratas, isto é, como diz textualmente, "idéias vindas daqui e dali" (Freud, [1915] 1974, v. XVI, p. 137).

Nesse artigo, Freud nos revela a forma como compreendia o trabalho da ciência, assinalando que o avanço do conhecimento não tolera qualquer rigidez, inclusive em se tratando de definições. Sabia, desde sempre, que contaria com o repúdio e a resistência às suas idéias, pois, afinal, seria esse o destino inexorável da ciência que inventou.

\section{Com Lacan}

"Não há ciência do homem, o que nos convém entender no mesmo tom do 'não existem pequenas economias'. Não há ciência do homem porque o homem da ciência não existe, mas apenas seu sujeito" (Lacan, 1998, p. 873).

Falar em psicanálise é, também, falar em processo, em interação e em desprendimento ao se tentar alcançar a verdade em realidades fixas e imutáveis. É abrir mão do tempo vigente, cronológico, é propor trabalhar em uma dimensão de tempo em que um sujeito se estrutura, se cria, se inventa, e que, por isso, é um tempo singular, inaplicável a outro, é um tempo que só tem lógica se considerado na dimensão da lógica da estrutura do sujeito em questão na psicanálise, o sujeito do inconsciente.

Lacan, em 1964, em seu Seminário 11, os quatro Conceitos Fundamentais da Psicanálise, nos adverte que o Inconsciente é "algo de não nascido, de não realizado, que fica em espera na área... não é nem ser nem não ser" (Lacan, 1964, p. 29).

Verificamos a insistência de Lacan em destacar o que para nós consiste na grande ruptura entre as ciências em geral e a psicanálise, ou seja, a natureza de seu objeto, o inconsciente. Ao afirmar que, para os pensamentos inconscientes, existe uma mera possibilidade de existência, Freud propõe um "conceito" de inconsciente que aponta mais para a desconstrução de uma idéia do que propriamente para um indicativo conceitual, desde os primórdios da psicanálise, exatamente entre os anos de 1893-1895, em seu artigo "Sobre a psicoterapia da histeria". Indagamo-nos: como algo que se apresenta como "nem ser, nem não ser", "não realizado", para o qual só existe a "mera 
possibilidade de existência", que só pode ser verificado e conhecido diretamente pela via da interpretação e que só se manifesta pela via de um sintoma e no sonho, no ato que falha e no chiste pôde vir a se constituir como "algo" que anseia pertencer a uma categoria científica?

Lacan, na sua lição "O objeto da psicanálise", publicada em seus Escritos sob o título "A ciência e a verdade", declara que o sujeito sobre o qual operamos em psicanálise só pode ser o sujeito da ciência, perguntando-se se o status de sujeito na psicanálise já fora fundamentado, uma vez que o que se pôde estabelecer foi "uma estrutura que dá conta do estado de fenda, de 'Spaltung' em que o psicanalista o situa em sua práxis" (Lacan, [1965-1966] 1998, p. 869). Tal fenda é admitida na base em que o reconhecimento do inconsciente basta para motivá-la na medida em que ela é que o faz submergir em sua constante tentativa de manifestar-se.

Lacan refere-se a essa origem indubitável, patente em todo trabalho de Freud com a ciência moderna organizada no século XVIII, que ilumina e é iluminada pelo pensamento de René Descartes.

Freud, ao contrário do que se diz, não teria rompido com o cientificismo de seu tempo, pois lhe foi fiel, e, se quisermos, como nos indica Lacan, vincularemos tal fidelidade aos ideais de um Brücke, aquele grande cientista que tanto o teria impressionado.

Lacan assinala, ainda, a fidelidade de Freud aos princípios de sua época, transmitidos através do pacto com que Helmholtz e Du
Bois-Reymond se haviam comprometido, isto é, o de "introduzir a fisiologia e as funções do pensamento, consideradas como incluídas neles, em termos matematicamente determinados da termodinâmica" (ibid., p. 870).

Freud teria, de acordo com Lacan, se conservado nesse ideário, permitindo-se conduzir por esse fio, estando sempre de acordo com ele, tendo-se mantido rigorosamente comprometido com os ideais cientificistas de sua época, pois, como os grandes cientistas de seu tempo, foi um partidário da crença de que a ciência tudo poderia explicar.

Refletimos, por meio dessas verificações possíveis com a leitura de "A ciência e a verdade", que talvez a publicação de $A$ Interpretação dos Sonhos, em 1900, não tenha sido obra do acaso ou de um atraso: Freud já estava com o livro pronto em meados de 1899 e só autorizou sua publicação na virada do século, marcando para nós a virada que a sua ciência apresenta ao mundo. Nessa obra, propõe o "seu" inconsciente, propositalmente aqui escrito entre aspas, na medida em que é um "seu", proposto amplamente, visto que se distingue do inconsciente da Filosofia, e também é "seu" por ter-se permitido invadir, expondose, revelando ao mundo os seus sonhos, o seu próprio inconsciente.

As conferências e entrevistas que foram proferidas por Lacan, entre os meses de novembro e dezembro de 1975, em universidades norte-americanas, são aqui convocadas por terem oferecido uma medida de como ele próprio considerava o termo ciência aplicado à psicanálise. 
Entrevistado por Mme lurkell sobre a forma como ele articularia a idéia de que a psicanálise aspira ao status de ciência com o que ele já se teria referido como epidemia, um fenômeno social, Lacan responde que uma epidemia não é um fenômeno social, pelo menos no caso da ciência, e que uma epidemia científica acontece quando alguma coisa é tomada como uma simples emergência, enquanto é, de fato, uma ruptura radical. É um acontecimento histórico que se propagou e que influenciou muito a concepção daquilo que se chama universo, que, em si mesma, tem uma base muito estreita, salvo no imaginário.

A psicanálise é, então, apresentada por Lacan como uma epidemia científica, visto que se propaga e abre novas concepções sobre aquilo que se chama universo. É uma ciência moderna na medida em que, com a modernidade, esteve sempre comprometida.

Segundo Lacan, a descoberta de Freud inaugura um discurso inédito, uma nova modalidade de laço social, a partir da qual podemos pensar retroativamente as outras modalidades já existentes desde sempre na civilização (Lacan, 1970/1992).

No discurso do analista, o sujeito é o sujeito do desejo dividido pelo recalque e pelo sintoma. É o mesmo sujeito da ciência, movido pelo desejo de saber, porém sua posição discursiva não é a de agente (como pode ser no discurso da ciência).

De acordo com o discurso do analista, o objeto é ativo, é o próprio analista, movido em seu ato pelo saber do inconsciente. Difere pois, radicalmente, do objeto da ciência, que é sempre o objeto da realidade empírica e não da realidade psíquica (fantasia) e que é, além disto, passivo diante do desejo do experimentador. O saber do inconsciente, cada analista obtém às suas próprias custas no divã durante a análise à qual se submete como sujeito. É, portanto, um saber que envolve uma "práxis" e que não se transmite apenas pela via do conhecimento, mas, sobretudo, pela experiência.

Lacan não é tão preciso ao falar do discurso da ciência. Como a maioria dos pensadores, atribui o advento da ciência moderna a Descartes, que promoveu a separação entre o campo da ciência e o da religião. No Seminário XI, Lacan nos diz:

“O que procura Descartes? é a certeza. Tenho, diz ele, extremo desejo de distinguir o verdadeiro do falso - sublinhem desejo para ver claro - no que? - em minhas ações e caminhar com segurança nesta vida" (Lacan, [1964] 1979, p. 210).

Ele chama a atenção para o fato de que Descartes propõe o seu método - a dúvida metódica - como um método próprio, que serve para ele e que ele não impinge aos outros. Seria nesse ponto que Descartes encontraria um novo caminho: ele não visa à refutação dos «saberes incertos» (ibid., p. 211). Ele abre seu caminho pela via do desejo, desejo de certeza. É a partir do desejo que ele chega à dúvida. Segundo Lacan, para Descartes, «a certeza não é [...] um momento que se possa ter como assentado, uma vez que foi atravessado. É uma ascese» (ibid., p. 212). Com seu método, ele põe em suspensão radical todos os saberes, mas para 
colocá-los no nível do sujeito suposto saber, Deus.

No entanto, ao evocar Deus nesse lugar de saber, Descartes inaugura, ao mesmo tempo, uma ciência "com a qual Deus nada tem a ver" (ibid., p. 214). A Deus pertencem as verdades eternas, mas cabe ao homem percorrer os caminhos que o levem a sua verdade.

Lacan ora nos diz que o discurso da ciência apaga o sujeito na medida em que não leva em conta o inconsciente e o desejo, o que se aproximaria do discurso do mestre, no qual o sujeito está oculto, ora nos diz que o discurso da ciência se aproxima do discurso da histérica, no qual o agente é o próprio sujeito do desejo.

A questão não é simples, pois, como observa Marco Antonio Coutinho Jorge (2002), Lacan deixou em aberto a possibilidade de formularmos outros discursos para além dos quatro que apresentou. O importante para nossa pesquisa é que, ao separar o campo do saber da psicanálise do campo da ciência, Lacan abriu novas perspectivas para a investigação psicanalítica.

Segundo Colette Soler (1996, p. 73), o correlato do sujeito cartesiano é a elisão do corpo na teoria de Descartes. Por isso, quando Descartes tenta pensar todo o registro do afeto e das paixões, defronta-se com uma dificuldade teórica. O corpo elidido é o corpo da sensibilidade, do sofrimento, do gozo. "Freud, portanto, complementa Descartes na medida em que introduz a idéia de que o pensamento está encarnado" (ibid., p. 73).

Em "A ciência e a verdade", verifica-se, de acordo com a análise feita por Askafaré, que o objetivo de Lacan é apontar que a psicanálise e determinadas disciplinas têm em comum o fato de que sua submissão às exigências das ciências físicas é simplesmente suicida. Freud, por ter partido da necessidade imperiosa de justificar racionalmente uma prática clínica original, distancia-se de Lacan, uma vez que se teria engajado na construção de um sistema orgânico de conceitos que lhe permitiram fundar a ciência psicanalítica e constituir o seu campo de saber naquilo que tornou possível avaliar o sentido e o alcance de sua descoberta.

"A ciência permanece sendo um ideal e a cientificidade da psicanálise um projeto, o programa freudiano" (Askafaré, 2002). Askafaré concebe o ponto de distanciamento entre Freud e Lacan na medida em que, neste último, pode ser identificada uma destituição do ideal da ciência, ou, melhor dizendo, destituição da ciência como ideal da psicanálise.

Freud, mesmo nos revelando sua consciência sobre a impossibilidade de seu projeto ser autorizado como um saber ideal, ou seja, científico, luta contra o que seria o destino inexorável do conhecimento que propôs ao mundo: provocar resistências, subverter saberes, viver sob o anátema da maioria compacta. 
Regina Coeli Aguiar Castelo Prudente Mestre em Psicologia, é Professora

Titular de História da Psicologia no

Centro de Ensino Superior de Juiz de Fora e Maria

Maria Anita Carneiro Ribeiro

Mestre em Psicologia Clínica pela PUCRJ e Pós-Doutora pela PUC-RJ, é Coordenadora da Especialização em

Psicologia Clínica da PUC-RJ

Av. Barão do Rio Branco, 1.727

Centro - 36013 - Juiz de Fora-MC

Telefone: (32) 3215-3319

E-mail: atendimento@neoclinica.com.br.

ASKAFARÉ. S. Da Ciência à Psicanálise. Trad. Vera Pollo (inédito),2002.

BIRMAN, J. Psicanálise, Ciência e Cultura. Rio de Janeiro: Jorge Zahar, 1987 .

FREUD, S. A História do Movimento Psicanalítico. A História do Movimento Psicanalítico, Artigos sobre Metapsicologia e outros Trabalhos. Trad. Themira de Oliveira Brito; Paulo Henrique Britto: Christiano Monteiro Oiticica, Rio de Janeiro: Imago (Edição standard brasileira das obras completas de Sigmund Freud, v. XIV) (1914)1974, pp. 13-119.

A Psicoterapia da Histeria. Estudos sobre a Histeria. Trad. Christiano Monteiro Oiticica. Rio de Janeiro: Imago (Edição standard brasileira das obras completas de Sigmund Freud, v. 11) (1893-1895)1974, pp.251-295.

Psicologia de Grupo e Análise do Ego. Além do Princípio de Prazer, Psicologia de Grupo, Análise do Eu e outros Trabalhos. Trad. Christiano Monteiro Oiticica. Rio de Janeiro: Imago (Edição standard brasileira das obras completas de Sigmund Freud, v. XVIII) (1921)1987, pp.76-152.

Um Estudo Autobiográfico. Um Estudo Autobiográfico, Inibições, Sintomas e Ansiedades. A Questão da Análise Leiga e outros Trabalhos. Trad. Christiano Monteiro Oiticica. Rio de Janeiro: Imago (Edição standard brasileira das obras completas de Sigmund Freud, v. XX) 1976, pp. 13-92.

JAPIASSU, Hilton. Psicanálise: Ciência ou Contra-ciência? Rio de Janeiro: Imago, 1989.
JONES, Ernest. Vida e Obra de Sigmund Freud. Rio de Janeiro: Jorge Zahar, 1961.

JORGE, M. A. C. Discurso e Crime Social. Saber, Verdade e Gozo. Rio de Janeiro: Rios Ambiciosos, 2002.

KUHN, T. S. A Estrutura das Revoluções Científicas. São Paulo: Perspectiva, 1970.

LACAN. J. A Ciência e a Verdade. Escritos. Trad. Vera Ribeiro. Rio de Janeiro: Jorge Zahar, 1998.

Conferências e Entrevistas nas Universidades Norte-americanas. Trad. Cyro Marcos da Silva. Juiz de Fora: Ato Freudiano/Grupo de Trabalho Intercartéis de Juiz de Fora (1975) 1996.

O Seminário, Livro 11: os quatro Conceitos Fundamentais da Psicanálise. Trad. M. D. Magno. Rio de Janeiro: Jorge Zahar (1964) 1985.

Psicoanalisis y Medicina. Intervenciones y Textos. Buenos Aires: Manantial, 1985.

O Seminário, Livro 17: o Avesso da Psicanálise. Rio de Janeiro: Jorge Zahar (1970) 1992.

ROZA, Luiz Alfredo Garcia. Freud e o Inconsciente. Rio de Janeiro: Jorge Zahar, 1996.

SOLER, C. Descartes con Freud. Psicoanalisis y Medicina. Buenos Aires: Actuel, 1996. 